\title{
Kinetics and Mechanism of Oxidation of L-proline by Trivalent Copper: A free radical intervention and decarboxylation
}

\author{
M. I. HIREMATH, R. S. SHETTAR and S. T. NANDIBEWOOR* \\ P. G. Department of Studies in Chemistry, \\ Karnatak University, \\ Dharwad-580003, India. \\ E-Mail: stnandibew oor@yahoo.com
}

Received 28 May 2004; Accepted 10 August 2004

\begin{abstract}
The kinetics of oxidation of L-proline by diperiodatocuprate(III) (DPC) in aqueous alkaline medium at a constant ionic strength of $0.10 \mathrm{~mol} \mathrm{dm}^{-3}$ was studied spectrophotometrically. The reaction between DPC and L-proline in alkaline medium exhibits 2:1 stoichiometry (DPC: L-Proline). The reaction is of first order in [DPC], less than unit order in [L-proline] and [alkali]. Periodate has no effect on the rate of reaction. The reaction rate increases with increase in ionic strength and decrease in solvent polarity of the medium. Effect of added products and ionic strength of the reaction medium have been investigated. The main products were identified by spot test and I.R spectra. A mechanism involving the DPC as the reactive species of the oxidant and a complex formation with L-proline has been proposed. The reaction constants involved in the different steps of mechanism are calculated. The activation parameters with respect to slow step of the mechanism are computed and discussed and thermodynamic quantities are also calculated.
\end{abstract}

Key words Kinetics; Diperiodatocuprate(III); Oxidation; L-proline;

\section{Introduction}

The periodate and tellurate complexes of copper in its trivalent state have been extensively used in the analysis of several organic compounds ${ }^{1}$. The kinetics of self-decomposition of these complexes were studied in some detail ${ }^{2}$. Diperiodatocuprate (III) (DPC) is a versatile one-electron oxidant for various organic compounds in alkaline medium and its use as an analytical reagent is now well recognized and also used in estimation of amino acids $^{3}$. Movius ${ }^{4}$ reported the reactivity of some alcohols with DPC. Copper (III) is shown to be an intermediate in the $\mathrm{Cu}(\mathrm{II})$ catalysed oxidation of amino acids by peroxdisulphate ${ }^{5}$. The use of diperiodatocuprate (III) as an oxidant in alkaline medium is new and restricted to a few cases due to the fact of its limited solubility and stability in aqueous medium ${ }^{6}$. Moreover, when the coppe (III) periodate complex is an oxidant, since multiple equilibria between the different copper(III) species are involved, it needs to be known which of species is the active oxidant.

Amino acids have been oxidised by a variety of oxidising agents ${ }^{7}$. The oxidation of amino acids is of interest as the oxidation products differ for different oxidant $s^{8,9}$. The study of amino acids becomes 
important because of their biological significance and selectivity towards the oxidant to yield different products. L- proline is a non-essential amino acid and is an important constituent of collagen. As per recent report ${ }^{10}$, L-proline is considered to be the world's smallest natural enzyme and it is used in catalysing the aldol condensation of the acetone to various aldehydes with high stereo-specificity that has the pace. Literature survey reveals that there are no reports on the oxidative mechanism of Lproline by diperiodatocuprate(III) (DPC) oxidant. The present study deals with the title reaction to investigate the redox chemistry of copper(III) in such media and to arrive at a plausible mechanism of the reaction on the basis of kinetic and spectral results.

The kinetic measurements were performed on a Peltier Accessory (temperature control) attached Varian CARY 50 Bio uv - vis spectrophotometer and IR studies were performed by Nicolet Impact - 410 FTIR.

\section{Materials: Chemicals}

All chemicals used were of reagent grade. Double distilled water was used throughout the work. Stock solution of L-proline (sd-fine chem.) was prepared by dissolving the appropriate amount of recrystallised sample in doubly distilled water. The purity of the sample was checked by TLC. The copper(III) periodate complex was prepared by standard procedure ${ }^{11}$. The purity of the complex was checked by its UV/Visible spectrum, which showed a broad absorption band at $415 \mathrm{~nm}$. The aqueous solution of copper(III) was standardized by back titration ${ }^{12}$ method. Dissolving the known amount of copper sulphate $(\mathrm{BDH})$ in distilled water made the $\mathrm{Cu}(\mathrm{II})$ solution. Periodate solution was prepared by weighing out the required amount of sample in hot water and it was kept for 24 hours. Its concentration was ascertained iodometrically ${ }^{13}$ at neutral $\mathrm{pH}$ by phosphate buffer. $\mathrm{KOH}$ and $\mathrm{KNO}_{3}(\mathrm{BDH}$, $\mathrm{AR}$ ) were employed to maintain the required alkalinity and ionic strength respectively in reaction solutions.

\section{Kinetic measurements}

The oxidation of L-proline by DPC was followed under pseudo- first order conditions where L-proline was excess over [DPC] at $25 \pm 0.1^{\circ} \mathrm{C}$, unless otherwise stated. The reaction was initiated by mixing the required quantities of previously thermostatted solution of L-proline and [DPC], which also contained definite quantities of $\mathrm{KOH}, \mathrm{KNO}_{3}$ and $\mathrm{IO}_{4}^{-}$to maintain the required alkalinity, ionic strength and periodate. Here the total concentration of hydroxide ion was calculated considering the $\mathrm{KOH}$ in DPC as well as the $\mathrm{KOH}$ additionally added. Similarly, the total metaperiodate concentration was calculated by considering metaperiodate present in solution of DPC and additionally added. The course of reaction was followed by measuring the absorbance of unreacted DPC in the reaction mixture in a $1 \mathrm{~cm}$ quartz cell located in the thermostatted compartment of a Peltier Accessory (temperature control) attached Varian CARY 50 Bio uv-vis spectrophotometer at its maximum absorption wavelength of $415 \mathrm{~nm}$ as a function of time. Earlier it was mixture at this wavelength. The obedience of Beer's verified that there is negligible interference from other species present in the reaction law by DPC at $415 \mathrm{~nm}$ was verified earlier and the molar absorbance coefficient, 'å was found to be $6213 \pm 310 \mathrm{dm}^{3} \mathrm{~mol}^{-1} \mathrm{~cm}^{-1}$ at this wavelength (Figure 1 ). The first order rate constants, $k_{\text {obs, }}$ were obtained from the plots of log [Absorbance] vs time. The plots were linear up to about $75 \%$ completion of the reaction and the rate constants were reproducible within $\pm 5 \%$. Since periodate is present in excess in DPC, the possibility of oxidation of L-proline by periodate in alkaline medium at $25^{\circ} \mathrm{C}$ was tested. The progress of the reaction was followed iodometrically. However, it was found that there was no significant reaction under the experimental conditions employed compared to the DPC oxidation of L-proline.

The effect of dissolved oxygen on the rate of reaction was studied by preparing the reaction mixture and following the reaction in an atmosphere of nitrogen. No significant difference between the results was observed. In view of the ubiquitous contamination of basic solutions by carbonate, the effect of carbonate on the reaction was also studied. Added carbonate had no effect on reaction rate. However, fresh solutions were used during the experiments.

In view of the modest concentration of alkali used in the reaction medium, attention was also given to the effect of the surface of the reaction vessel on the kinetics. The use of polythene or acrylic ware and quartz or polyacrylate cells gave the same results, indicating that the surface does not have any significant effect on the rate.

Regression analysis of experimental data to obtain the regression coefficient $r$ and standard deviation S of points from the regression line was performed using a Pentium-IV personal computer. 


\section{Results}

Stoichiometry and product analysis

Different sets of reaction mixtures containing excess DPC than L-proline with constant $\mathrm{OH}^{-}$and $\mathrm{KNO}_{3}$ were kept for $6 \mathrm{hrs}$ in closed vessel under nitrogen atmosphere. The remaining concentration of DPC was estimated by spectrophotometrically at $415 \mathrm{~nm}$. The results indicated 2:1 stoichiometry as given in $\mathrm{Eq}(1)$.

$\mathrm{NH}-\mathrm{CH}_{2}-\mathrm{CH}_{2}-\mathrm{CH}_{2}-\mathrm{CH}_{-} \mathrm{COOH}+2 \mathrm{Cu}(\mathrm{III})+2 \mathrm{OH}^{-} \rightarrow \mathrm{H}_{2} \mathrm{~N}-\mathrm{CH}_{2}-\mathrm{CH}_{2}-\mathrm{CH}_{2}-\mathrm{CHO}+2 \mathrm{Cu}(\mathrm{II})+\mathrm{H}_{2} \mathrm{O}+\mathrm{CO}_{2}$

The main reaction products were identified as the aminobutaraldehyde by spot test ${ }^{14}$ for amine and aldehyde groups. The product, aminobutaraldehyde was also confirmed by IR spectroscopy ${ }^{15}$ which showed bands at $3444 \mathrm{~cm}^{-1}$ for NH stretching, $1773 \mathrm{~cm}^{-1}$ for aldehydic $>C O$ stretching and $2956 \mathrm{~cm}^{-1}$, for aldehydic $-\mathrm{CH}$ stretching respectively. The only organic product obtained in the oxidation is aminobutaraldehyde,which is further confirmed by single spot in TLC.However,the other product in alkaline medium is copper(II), identified by spot test ${ }^{16}$ and uv-visible spectra. Test for the corresponding acid was negative. It was further observed that the aldehyde does not undergo further oxidation under prevailing kinetic conditions.

Reaction orders

The order with respect to [L-proline], [alkali] and [periodate] were found by log $k_{\text {obs }}$ vs log concentration plots and the obtained orders were also confirmed by differential method by the plot log(-dc/dt) vs log concentration using the equation $\log ( \pm d c / d t)=\log k+n \log c$; these orders were obtained by varying the concentration of L-proline, periodate and alkali in turn while keeping others constant.

Figure 1. Verification of Beer's law for [DPC] at $415 \mathrm{~nm}$ in $0.02 \mathrm{~mol} \mathrm{dm}^{-3}$ alkali.

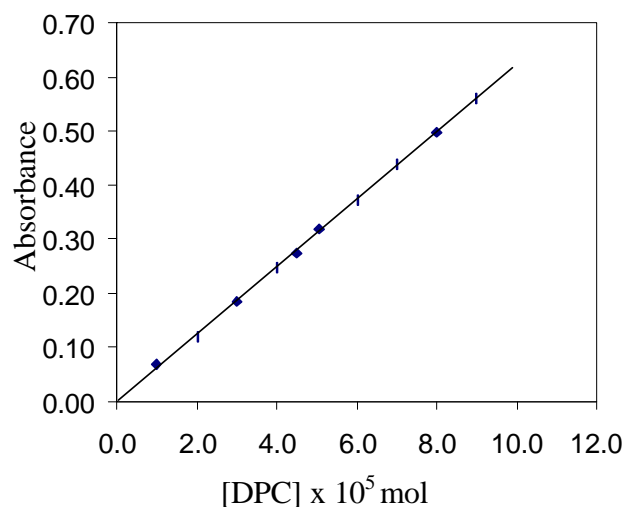

The diperiodatocuprate(III) concentration was varied in the range, $2.0 \times 10^{-5}$ to $2.0 \times 10^{-4} \mathrm{~mol} \mathrm{dm}^{-3}$ and linearity of plots of log[Abs] vs time $(r>0.9994, S \measuredangle 0.026)$ up to $75 \%$ completion of the reaction (Figure2) indicate the order in [diperiodatocuprate(III)] as unity. This result was also confirmed by varying the [diperiodatocuprate(III)] which did not show any change in pseudo-first order rate constants $\left(\mathrm{k}_{\text {obs }}\right)$ (Table 1$)(\mathrm{r}>0.9994, \mathrm{~S} \leq 0.026)$. The substrate, L-proline was varied in the range of $5.0 \times 10^{-4}$ to $5.0 \times 10^{-3}-\mathrm{mol} \mathrm{dm}^{-3}$ at $250 \mathrm{C}$ keeping all other reactants concentrations constant. The $\mathrm{k}_{\text {obs }}$ values increased with increase in concentration of L-proline indicating an apparent less than unit order dependence on [L-proline] (Table 1). The effect of [alkali] on the rate of reaction was studied at constant concentrations of L-Proline, DPC and ionic strength at $0.10 \mathrm{~mol} \mathrm{dm}^{-3}$. The rate constants increased with increase in [alkali] and the order was found to be less than unity (Table 1).

Effect of relative permittivity and ionic strength

The effect of relative permitivity $\left(\epsilon_{T}\right)$ was studied by varying the t-butanol-water content in the reaction mixture with all other conditions being maintained constant. Attempts to measure the relative permittivities were not successful. However, they were computed from the values of pure liquids ${ }^{17}$. 
The solvent did not react with the oxidant under the experimental conditions. The rate constant, $\mathrm{k}_{\mathrm{obs}}$ increased with decreasing dielectric constant of the medium. The plot of log $\mathrm{k}_{\mathrm{obs}}$ versus.1/ $\int_{T}$ was linear with a positive slope (Figure.3). The effect of ionic strength was studied by varying the $\mathrm{KNO}_{3}$ concentration in the reaction medium. The ionic strength was varied from 0.05 to $0.25 \mathrm{~mol} \mathrm{dm}^{-3}$ at constant concentrations of diperiodatocuprate(III), L-proline and alkali. It was found that the rate constant increased with increasing concentration of $\mathrm{KNO}_{3}$; the plot of log $\mathrm{k}_{\text {obs }}$ versus. $\mathrm{I}^{1 / 2}$ was linear with a positive slope (Figure 3) $(r>0.9978, \mathrm{~S} \leq 0.018)$.

Figure 2. First order plots of oxidation of diperiodatocuprate(III) by L-proline in aqueous alkaline medium at $25^{\circ} \mathrm{C}$.
$[\mathrm{DPC}] \times 10^{4}\left(\mathrm{~mol} \mathrm{dm}^{-3}\right) ;$
(1) 0.2
(2) 0.5
(3) 1.0
(4) 1.5
(5) 2.0

Time (Min)

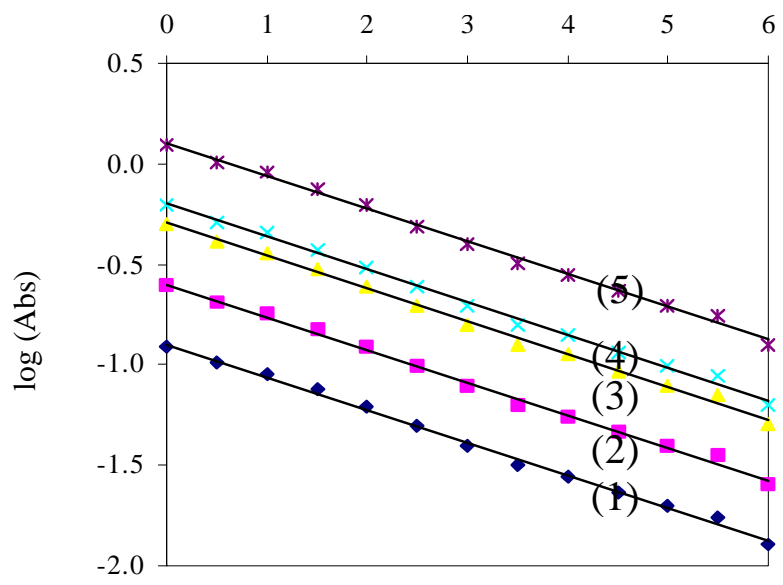

Figure 3. Effect of ionic strength (I) and relative permitivity $\left(\epsilon_{\mathrm{T}}\right)$ on the DPC oxidation of L-proline in aqueous alkaline medium at $25^{\circ} \mathrm{C}$

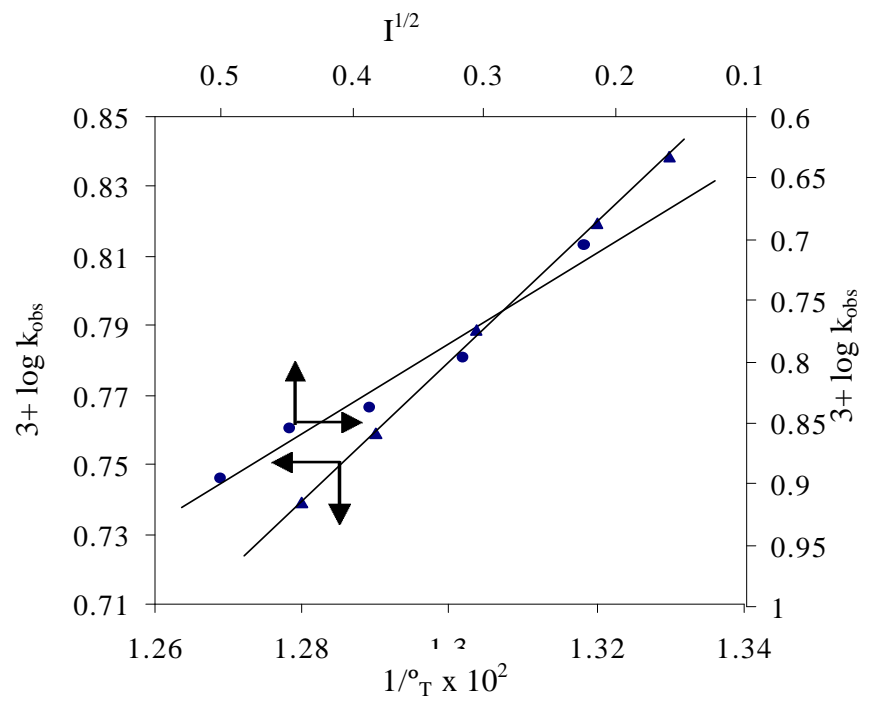


Effect of initially added products

The externally added products, $\mathrm{Cu}(\mathrm{II})$ in the form of copper sulphate and another product aminobutaraldehyde did not have any significant effect on the rate of the reaction.

Test for Free Radicals

To test the intervention of free radicals, the reaction mixture was mixed with acrylonitrile monomer and kept for 24 hours under nitrogen atmosphere. On dilution with methanol, white precipitate of polymer was formed, indicating the presence of intervention of free radicals in the reaction. The blank experiment of either DPC or L-proline in which acrylonitrile alone did not induce polymerization under the same condition as those induce with reaction mixture. Initially added acrylonitrile decreases the rate indicating the free radical intervention, which is the case in earlier work ${ }^{18}$.

Effect of periodate

The effect of $\left[\mathrm{IO}_{4}^{-}\right]$was observed by varying the concentration from $1.0 \times 10^{-5}$ to $1.0 \times 10^{-4} \mathrm{~mol} \mathrm{dm}^{-3}$ keeping all other reactants concentrations constant. It was found that the added periodate has no effect on the rate of reaction.

Effect of temperature

The rate of reaction was measured at different temperatures under varying L-proline concentration. The rate of reaction increased with the increase of temperature. The rate constants, $k$ of slow step of Scheme 1 were obtained from intercepts of the plots of $1 / \mathrm{K}_{\text {obs }}$ Vs $1 /$ [L-proline] $(r>0.9978, S \leq 0.0162)$ at

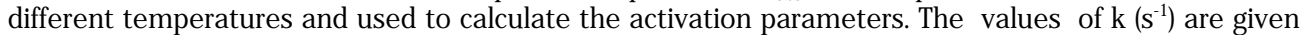
in table 2. The activation parameters corresponding to these constants were evaluated from the plot of log $\mathrm{k}$ vs $1 / \mathrm{T}(r>0.9989, \mathrm{~S} \varangle 0.0135)$ and are tabulated in table 2 .

Table 1. Effect of variation of [DPC], [SAL], $\left[\mathrm{OH}^{-}\right]$, and $\left[\mathrm{IO}_{4}^{-}\right]$on oxidation of L-Proline by DPC at $25^{\circ} \mathrm{C}$, $\mathrm{I}=0.10 \mathrm{~mol} \mathrm{dm}^{-3}$.

\begin{tabular}{cccccc}
\hline $\begin{array}{c}{[\mathrm{DPC}] \times 10^{4}} \\
\left(\mathrm{~mol} \mathrm{dm}^{-3}\right)\end{array}$ & $\begin{array}{c}\text { [L-Poline }] \times 10^{3} \\
\left(\mathrm{~mol} \mathrm{dm}^{-3}\right)\end{array}$ & $\begin{array}{c}{\left[\mathrm{OH}^{-}\right]} \\
\left(\mathrm{mol} \mathrm{dm}^{-3}\right)\end{array}$ & $\begin{array}{c}\left.\mathrm{IIO}_{4}^{-}\right] \times 10^{5} \\
\left(\mathrm{~mol} \mathrm{dm}^{-3}\right)\end{array}$ & $\begin{array}{c}\text { Found. } \\
\text { Found }\end{array}$ & Calc. \\
\hline 0.2 & & 0.02 & 1.0 & 6.23 & 6.50 \\
0.4 & 1.0 & 0.02 & 1.0 & 6.24 & 6.50 \\
0.8 & 1.0 & 0.02 & 1.0 & 6.20 & 6.50 \\
1.0 & 1.0 & 0.02 & 1.0 & 6.25 & 6.50 \\
2.0 & 1.0 & 0.02 & 1.0 & 6.19 & 6.50 \\
1.0 & 1.0 & 0.02 & 1.0 & 3.80 & 3.75 \\
1.0 & 0.5 & 0.02 & 1.0 & 6.25 & 6.50 \\
1.0 & 1.0 & 0.02 & 1.0 & 10.3 & 10.50 \\
1.0 & 2.0 & 0.02 & 1.0 & 15.0 & 14.90 \\
1.0 & 3.0 & 0.02 & 1.0 & 18.5 & 16.50 \\
1.0 & 5.0 & 0.01 & 1.0 & 3.90 & 3.86 \\
1.0 & 1.0 & 1.0 & 6.25 & 6.50 \\
1.0 & 1.0 & 0.02 & 1.0 & 10.0 & 9.98 \\
1.0 & 1.0 & 0.04 & 1.0 & 14.4 & 14.3 \\
1.0 & 1.0 & 0.08 & 1.0 & 16.8 & 15.6 \\
1.0 & 1.0 & 0.10 & 1.0 & 6.25 & 6.50 \\
1.0 & 1.0 & 0.02 & 2.0 & 6.03 & 6.50 \\
1.0 & 1.0 & 0.02 & 4.0 & 6.13 & 6.50 \\
1.0 & 1.0 & 0.02 & 8.0 & 6.23 & 6.50 \\
1.0 & 1.0 & 0.02 & 10.0 & 6.31 & 6.50 \\
\hline
\end{tabular}


Table 2. Thermodynamic activation parameters for the oxidation of diperiodatocuprate(III) by L-proline in alkaline medium with respect to the slow step of Scheme 1

(A) Effect of temperature

\begin{tabular}{cc}
\hline Temp. (K) & $\mathrm{k} \times 10^{-2}\left(\mathrm{~s}^{-1}\right)$ \\
\hline 298 & 2.66 \\
303 & 3.16 \\
308 & 3.92 \\
313 & 4.78 \\
\hline
\end{tabular}

(B) Effect of temperature to calculate $\mathrm{K}_{4}$ and $\mathrm{K}_{5}$ on oxidation of DPC by L-proline in alkaline medium.

\begin{tabular}{ccc}
\hline Temp. $(\mathrm{K})$ & $\mathrm{K}_{4}\left(\mathrm{dm}^{3} \mathrm{~mol}^{-1}\right)$ & $\mathrm{K}_{5} \times 10^{3}\left(\mathrm{dm}^{3} \mathrm{~mol}^{-1}\right)$ \\
\hline 298 & 2.64 & 8.58 \\
303 & 3.21 & 5.63 \\
308 & 4.26 & 3.31 \\
313 & 5.63 & 2.32 \\
\hline
\end{tabular}

C) Activation parameters

\begin{tabular}{|c|c|}
\hline Parameters & Values \\
\hline $\mathrm{H}^{\#}\left(\mathrm{~kJ} \mathrm{~mol}{ }^{-1}\right)$ & $29+1$ \\
\hline $\log A$ & $9.0 \pm 0.3$ \\
\hline $\mathrm{S}^{\#}\left(\mathrm{JK}^{-1} \mathrm{~mol}^{-1}\right)$ & $-181+10$ \\
\hline $\mathrm{G}^{\#}\left(\mathrm{~kJ} \mathrm{~mol}{ }^{-1}\right)$ & $55 \pm 4$ \\
\hline
\end{tabular}

(D) Thermodynamic quantities

\begin{tabular}{cc}
\hline Thermodynamic quantities & Values \\
\hline$\ddot{\mathrm{AH}}\left(\mathrm{k} \mid \mathrm{mol}^{-1}\right)$ & $39 \pm 1$ \\
$\ddot{\mathrm{AS}}\left(\mid \mathrm{K}^{-1} \mathrm{~mol}^{-1}\right)$ & $140 \pm 8$ \\
$\ddot{\mathrm{A} G}\left(\mathrm{k} \mid \mathrm{mol}^{-1}\right)$ & $-2.3 \pm 0.2$ \\
\hline
\end{tabular}

\section{Discussion}

The water soluble $\mathrm{Cu}(\mathrm{III})$ periodate complex is reported ${ }^{19}$ to be $\left[\mathrm{Cu}\left(\mathrm{HIO}_{6}\right)_{2}(\mathrm{OH})_{2}\right]^{7}$. However, in an aqueous alkaline medium and at a high $\mathrm{pH}$ range as employed in the study, periodate is unlikely to exist as $\mathrm{HIO}_{6}{ }^{4-}$ (as present in the complex) as is evident from its involvement in the multiple equilibria ${ }^{20}(2)-(4)$ depending on the $\mathrm{pH}$ of the solution. 


$$
\begin{array}{llll}
\mathrm{H}_{5} \mathrm{IO}_{6} \rightleftharpoons \mathrm{H}_{4} \mathrm{IO}_{6}^{-}+\mathrm{H}^{+} & \text {(2) } \mathrm{K}_{1}=5.0 \times 10^{-4} \\
\mathrm{H}_{4} \mathrm{IO}_{6}{ }^{-} \rightleftharpoons \mathrm{H}_{3} \mathrm{IO}_{6}{ }^{2-}+\mathrm{H}^{+} & \text {(3) } \mathrm{K}_{2}=4.9 \times 10^{-9} \\
\mathrm{H}_{3} \mathrm{IO}_{6}{ }^{-} \rightleftharpoons \mathrm{H}_{2} \mathrm{IO}_{6}{ }^{3-}+\mathrm{H}^{+} & \text {(4) } \mathrm{K}_{3}=2.5 \times 10^{-12}
\end{array}
$$

Periodic acid $\left(\mathrm{H}_{5} \mathrm{IO}_{6}\right)$ exists in acid medium and also as $\mathrm{H}_{4} \mathrm{IO}_{6}$ at $\mathrm{pH}$ 7. Thus, under alkaline conditions, the main species are expected to be $\mathrm{H}_{3} \mathrm{IO}_{6}{ }^{2-}$ and $\mathrm{H}_{2} \mathrm{IO}_{6}{ }^{3-}$. At higher concentrations, periodate also tends to dimerise. Hence, at the $\mathrm{pH}$ employed in this study, the soluble copper(III) periodate complex exists as diperiodatocuprate(III), $\left[\mathrm{Cu}\left(\mathrm{H}_{3} \mathrm{IO}_{6}\right)_{2}(\mathrm{OH})_{2}\right]^{3-}$ in aqueous alkaline medium, a conclusion also supported by earlier work ${ }^{4}$.

Periodic acid $\left(\mathrm{H}_{5} \mathrm{O}_{6}\right)$ exists in acid medium and also as $\mathrm{H}_{4} \mathrm{IO}_{6}$ at $\mathrm{pH}$ 7. Thus, under alkaline conditions, the main species are expected to be $\mathrm{H}_{3} \mathrm{IO}_{6}{ }^{2-}$ and $\mathrm{H}_{2} \mathrm{IO}_{6}{ }^{3-}$. At higher concentrations, periodate also tends to dimerise. Hence, at the $\mathrm{pH}$ employed in this study, the soluble copper(III) periodate complex exists as diperiodatocuprate(III), $\left[\mathrm{Cu}\left(\mathrm{H}_{3} \mathrm{IO}_{6}\right)_{2}(\mathrm{OH})_{2}\right]^{3-}$ in aqueous alkaline medium, a conclusion also supported by earlier work ${ }^{4}$.

The reaction between the L-proline and diperiodatocuprate(III) complex in alkaline medium has the stoichiometry $1: 2$ with a first order dependence on the [DPC] and a less than unit order dependence on the [alkali] and [substrate]. In most of the reports ${ }^{4}$ on DPC oxidation, periodate had retarding effect and order in the $\left[\mathrm{OH}^{-}\right]$was found to be less than unity and monoperiodatocuprate(III) is considered to be the active species. However, in the present kinetic study, different observations have been obtained i.e., periodate has totally no effect on the rate of the reaction. Accordingly, the DPC is considered to be the active species. No effect of added product such as copper (II) was observed.

It is known that L-proline exists in the form of Zwitter ion ${ }^{21}$ in aqueous medium. In highly acidic medium, it exists in the protonated form, whereas in highly basic medium, it is in the fully deprotonated form ${ }^{21}$.The observed fractional order in $\left[\mathrm{OH}^{-}\right]$indicate that first alkali combines with $\mathrm{Cu}^{3-}$

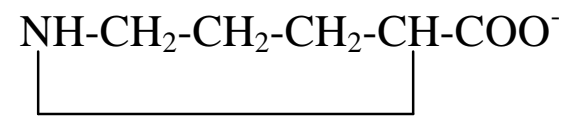

to form an alkali-DPC species $\left[\mathrm{Cu}(\mathrm{OH})_{2}\left(\mathrm{H}_{3} \mathrm{O}_{6}\right)\left(\mathrm{H}_{2} \mathrm{IO}_{6}\right)\right]^{4}$ in a pre-equilibrium step ${ }^{22}$, which is also supported by the Michaelis-Menten plot (Figure 4)which is linear with a positive intercept. L-proline in the deprotonated form reacts with alkali $\left[\mathrm{Cu}(\mathrm{OH})_{2}\left(\mathrm{H}_{3} \mathrm{O}_{6}\right)\left(\mathrm{H}_{2} \mathrm{O}_{6}\right)\right]^{4-}$ to form a complex $C$. This complex $\mathrm{C}$ decomposes in a slow step to give a free radical derived from decarboxylated L-proline.This radical in turn reacts with another molecule of DPC species in a fast step to yield the products (Scheme 1 ).

$$
\begin{aligned}
& {\left[\mathrm{Cu}(\mathrm{OH})_{2}\left(\mathrm{H}_{3} \mathrm{IO}_{6}\right)_{2}\right]^{3-}+\mathrm{OH}^{-} \stackrel{\mathrm{K}_{4}}{\rightleftharpoons}\left[\mathrm{Cu}(\mathrm{OH})_{2}\left(\mathrm{H}_{3} \mathrm{IO}_{6}\right)_{2}\left(\mathrm{H}_{2} \mathrm{IO}_{6}\right)_{2}\right]^{4-}+\mathrm{H}_{2} \mathrm{O}}
\end{aligned}
$$

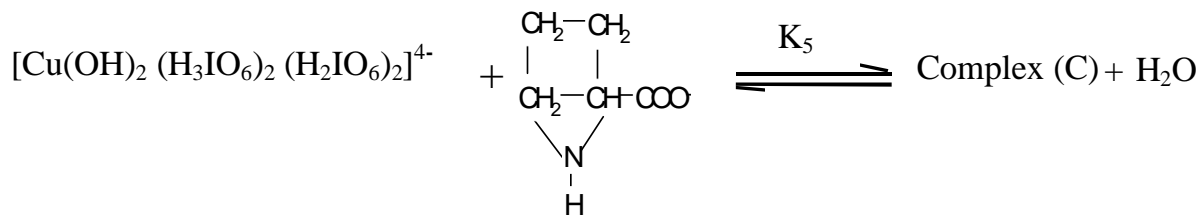

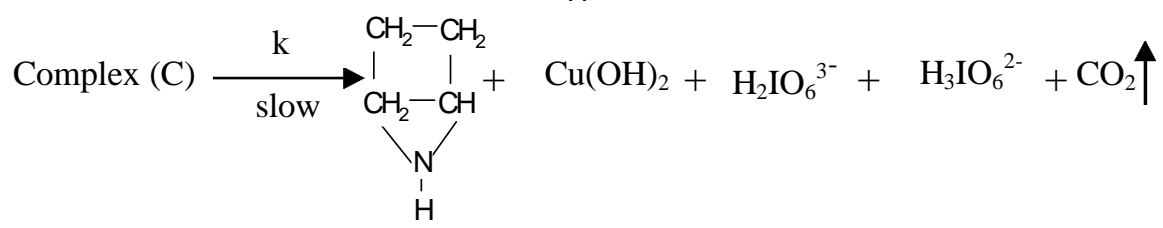




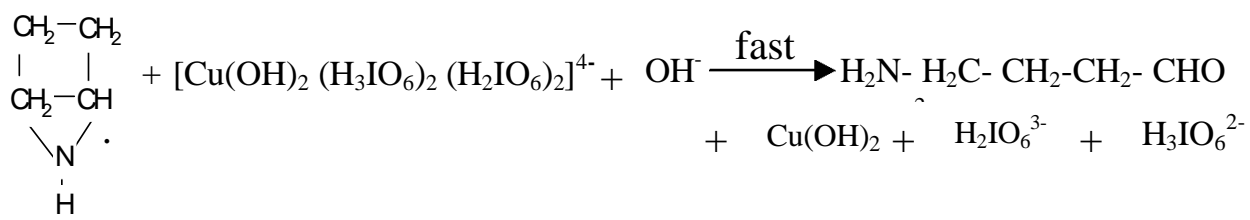

Scheme - 1

The probable structure of the complex $(\mathrm{C})$ is given below

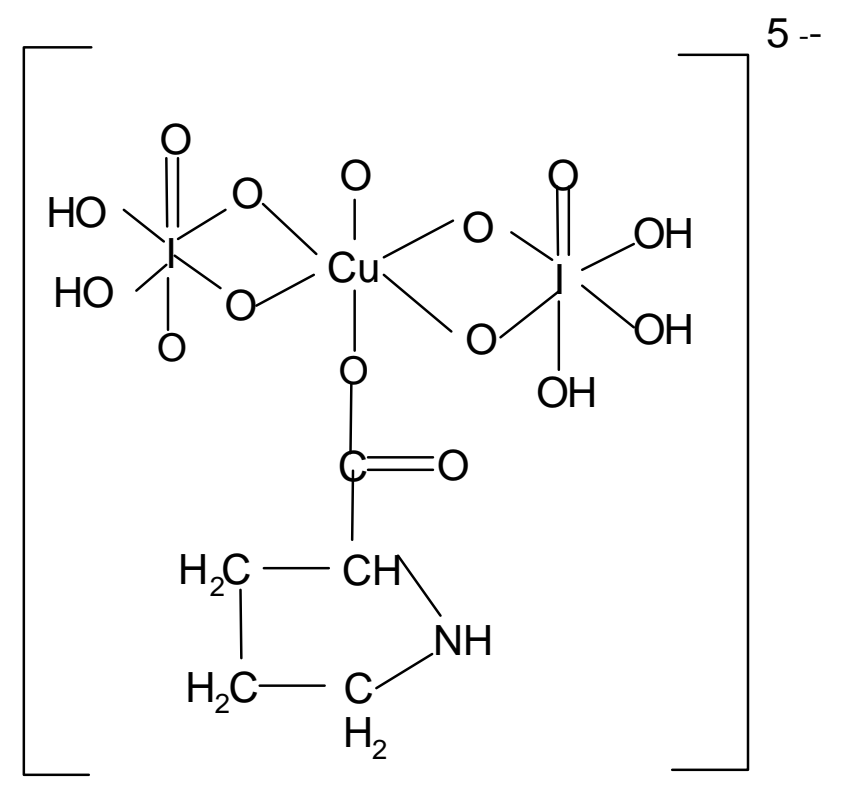

Spectral evidence of such a complex was obtained from the uv-vis spectra of, DPC, alkali and a mixture of L-proline,alkali and DPC. A hypochromic shift, $\ddot{e}_{\max }$ of ca.about $6 \mathrm{~nm} 416$ to $410 \mathrm{~nm}$ is observed together with hyperchromicity at $410 \mathrm{~nm}$. Such complex formation between the oxidant and substrate has been observed earlier ${ }^{23}$. Further, the evidence for complex formation is also proved by kinetic studies (i.e., from the Michaelis-Menten plot) by the non-zero intercept (Figure 4) $(r>0.9989, \mathrm{~S} \varangle 0.0135)$ of the plot of $1 / k_{\text {obs }}$ Vs $1 /$ [L-proline]. The mechanism is also supported by moderate values of activation parameters (Table 2). A high negative value of $\ddot{A} S^{\#}$ suggests that the intermediate complex is more ordered than the reactants. The observed modest enthalpy of activation and a relatively high rate constant of the slow step indicated that the oxidation presumably occurs via inner-sphere mechanism. This conclusion is supported by earlier observation ${ }^{24}$.Spectral evidence of such a complex was obtained from the uv-vis spectra of, DPC, alkali and a mixture of L-proline,alkali and DPC. A hypochromic shift, $\ddot{e}_{\max }$ of ca.about $6 \mathrm{~nm} 416$ to $410 \mathrm{~nm}$ is observed together with hyperchromicity at $410 \mathrm{~nm}$. Such complex formation between the oxidant and substrate has been observed earlier ${ }^{23}$. Further, the evidence for complex formation is also proved by kinetic studies (i.e., from the Michaelis-Menten plot) by the nonzero intercept (Figure 4) $(r>0.9989, \mathrm{~S} \leq 0.0135)$ of the plot of $1 / \mathrm{k}_{\text {obs }} \mathrm{VS} 1 /[\mathrm{L}$-proline]. The mechanism is also supported by moderate values of activation parameters (Table 2). A high negative value of $\ddot{A} S^{\#}$ suggests that the intermediate complex is more ordered than the reactants. The observed modest enthalpy of activation and a relatively high rate constant of the slow step indicated that the oxidation presumably occurs via inner-sphere mechanism. This conclusion is supported by earlier observation ${ }^{24}$. 
Since Scheme 1 is in accordance with the generally well accepted principle of non-complementary oxidations taking place in sequences of one-electron steps, the reaction would involve a radical intermediate. A free radical scavenging experiment revealed such a possibility (vide infra). This type of radical intermediate has also been observed in earlier work ${ }^{25}$ on alkaline-DPC oxidations of amino acids. Scheme 1 leads to the rate law given in Eq. (5).

$$
\begin{aligned}
& \text { rate }=-\frac{\mathrm{d}[\mathrm{DPC}]}{\mathrm{dt}}=\frac{\mathrm{kK}_{4} \mathrm{~K}_{5}[\mathrm{~L}-\text { proline }]\left[\mathrm{OH}^{-}\right][\mathrm{DPC}]}{\left(1+\mathrm{K}_{4}\left[\mathrm{OH}^{-}\right]+\mathrm{K}_{4} \mathrm{~K}_{5}\left[\mathrm{OH}^{-}\right][\text {L-proline }]\right)} \\
& \frac{1}{\left(1+\mathrm{K}_{4} \mathrm{~K}_{5}[\mathrm{DPC}]\left[\mathrm{OH}^{-}\right]\right)\left(1+\mathrm{K}_{4}\left[\mathrm{DPC}^{-}\right]+\mathrm{K}_{4} \mathrm{~K}_{5}[\mathrm{~L}-\text { proline }][\mathrm{DPC}]\right)}
\end{aligned}
$$

The terms $\left(1+\mathrm{K}_{4} \mathrm{~K}_{5}[\mathrm{DPC}]\left[\mathrm{OH}^{-}\right]\right)$and $\left(1+\mathrm{K}_{4}[\mathrm{DPC}]+\mathrm{K}_{4} \mathrm{~K}_{5}[\mathrm{~L}\right.$-proline][DPC]) in the denominator of Eq.(2) approximate to unity in view of the low concentration of DPC used $\left(K_{1}=2.64 a n d K_{2}=8588\right)$. Therefore, Eq.(5) becomes

Eq (6) can be rearranged to the following form (7), which is suitable for the verification of the rate law:

$$
\begin{aligned}
& \text { Rate } \quad \mathrm{kK}_{4} \mathrm{~K}_{5}[\mathrm{~L} \text {-proline }]\left[\mathrm{OH}^{-}\right]
\end{aligned}
$$

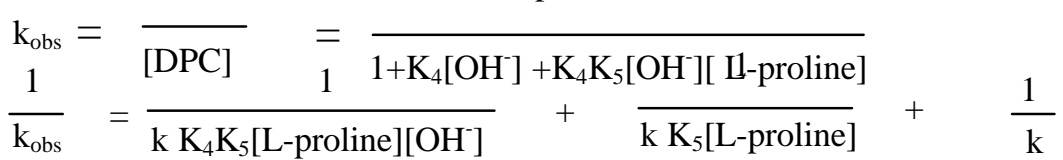

According to $\mathrm{Eq}(7)$, other conditions being constant, the plots of $1 / \mathrm{k}_{\text {obs }}$ vs $1 /[\mathrm{L}$-proline] $(r>0.9734$, $s \varangle 0.0138), 1 /\left[\mathrm{OH}^{-}\right](r>0.875, \mathrm{~s} \varangle 0.0217)$ should be linear (Figure 4), From the slopes and intercepts, the values of $\mathrm{K}_{4}, \mathrm{~K}_{5}$ and $\mathrm{k}$ could be derived as $2.64 \pm 1.0 \mathrm{dm}^{3} \mathrm{~mol}^{-1}, 8.58 \pm 0.3 \times 10^{3} \mathrm{dm}^{3} \mathrm{~mol}^{-1}$, and $2.66 \pm 0.10 \times 10^{-}$ ${ }^{2} \mathrm{~s}^{-1}$ respectively. Using these constants, the rate constants were calculated over different experimental conditions and there is a reasonable agreement between the calculated and experimental values Table 1, which fortifies the proposed mechanism.

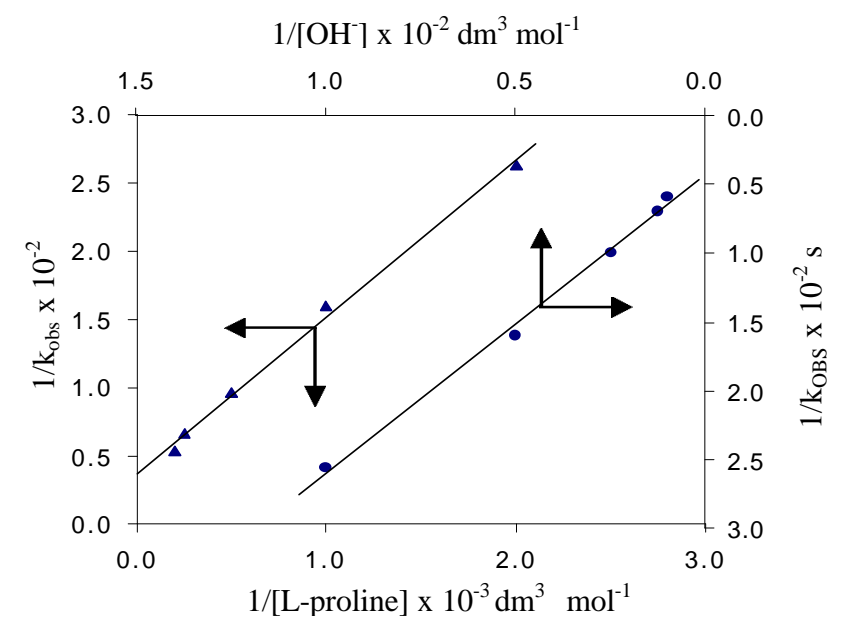

Figure 4. Verification of rate law (7) DPC oxidation of L-proline in aqueous alkaline medium at $25^{\circ}$ C.(Conditions as in Table 1) 
The thermodynamic quantities for the first equilibrium steps in Scheme 1 can be evaluated as follows: The hydroxyl ion concentration and L-proline concentration as in Table 1 were varied at four different temperatures and the $\mathrm{K}_{4}$ and $\mathrm{K}_{5}$ were determined at and are given in Table (2B). A Vant Hoff's plot was made for the variation of $K_{4}$ with temperature (i.e, log $K_{4}$ Vs $\left.1 / T\right)(r \geq 0.9781, s \leq 0.0108)$ and the corresponding thermodynamic quantities are given in Table (2D). A comparison of the latter values with those obtained for the slow step of the reaction shows that these values mainly refer to the rate limiting step, supporting the fact that the reaction before the rate determining step is fairly rapid and involves only high activation energy ${ }^{26}$.

The effect of increasing ionic strength on the rate explains qualitatively the reaction between two negatively charged ions, as seen in Schemel.However, increasing the content of t-butyl alcohol in the reaction medium leads to the increase in the reaction rate, contrary to the expected slower reaction between like ions in the media of lower relative permitivity. Perhaps the effect is countered substantially by the formation of active reactive species to a greater extent in low relative permitivity media leading to the net increase in rate ${ }^{27}$. The activation parameters for the oxidation of some amino acids by Diperiodatocuprate(III) are summarized in Table 3. The entropy of the activation for the title reaction falls within the observed range. Variation in the rate within a reaction series may be caused by change in the enthalpy and / or entropy of activation. Changes in the rate are caused by changes in both $\Delta \mathrm{H}^{\#}$ and $\Delta \mathrm{S}^{\#}$, but these quantities vary extensively in a parallel fashion. A plot of $\Delta \mathrm{H}^{\#}$ versus $\Delta S^{\#}$ is linear according to equation, $\beta$ is called the isokinetic temperature;

$$
\Delta \mathrm{H}^{\#}=\beta \Delta \mathrm{S}^{\#}+\text { constant }
$$

We have calculated the isokinetic temperature as $247.80 \mathrm{~K}$ by plotting $\Delta \mathrm{H}^{\#}$ versus $\Delta S^{\#}$ (Figure 5$)(r \geq$ $0.979 \& \mathrm{~s} \leq 0.0051)$. The value of $\beta(247.80 \mathrm{~K})$ is low er than experimental temperature range (298-313K). This indicates that the entropy of activation ${ }^{28}$ governs the rate. The linearity and the slope of the plot obtained may confirm that the kinetics of these reactions follow similar mechanism, as previously suggested.

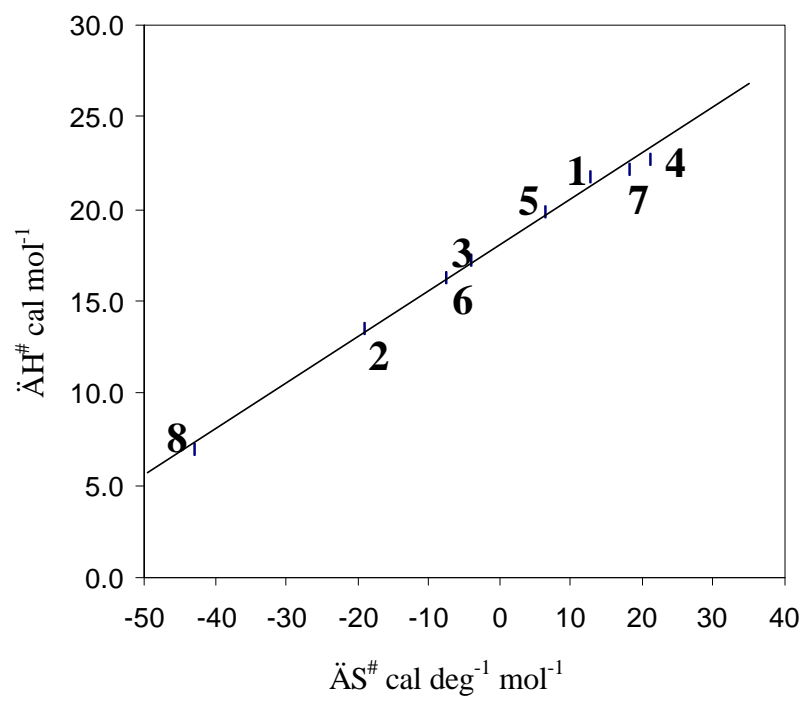

Figure 5. Isokinetic relation ship of $\ddot{\mathrm{AH}} \mathrm{H}^{\#}$ versus $\ddot{\mathrm{AS}} \mathrm{S}^{\#}$ plot for oxidations of some amino acids by Diperiodatocuprate(III).

1=Glycine ,2 =â-Alanine, 3 =á-Alanine, 4 =Phenylalanine, 5=Leucine, $6=$ Valine, 7 = Serine , 8= L-proline. 
Table 3. Activation parameters for some amino acids (for isokinetic temperature)

\begin{tabular}{ccccc}
\hline Amino acid & $\begin{array}{c}\Delta \mathrm{S}^{\#} \\
\left(\mathrm{cal} \mathrm{deg} \mathrm{mol}^{-1}\right)\end{array}$ & $\begin{array}{c}\Delta \mathrm{H}^{\#} \\
\left(\mathrm{k} \mathrm{cal} \mathrm{mol}^{-1}\right)\end{array}$ & $\begin{array}{c}\Delta \mathrm{G}^{\#} \\
\left(\mathrm{k} \mathrm{cal} \mathrm{mol}^{-1}\right)\end{array}$ & References \\
\hline Glycine & 12.6 & 21.8 & 18.0 & 29 \\
â-Alanine & -19.0 & 13.5 & 19.21 & 29 \\
á-Alanine & -4.10 & 17.2 & 19.2 & 29 \\
Phenylalanine & 21.0 & 22.7 & 16.3 & 29 \\
L-Leucine & 6.30 & 19.9 & 18.0 & 29 \\
L-Valine & -7.70 & 16.3 & 18.6 & 29 \\
Serine & 18.10 & 22.2 & 16.9 & Present Work \\
L-Proline & -43 & 7.0 & 13.2 & \\
\hline
\end{tabular}

\section{Conclusion}

Among various species of DPC in alkaline medium, $\left[\left(\mathrm{Cu}(\mathrm{OH})_{2}\left(\mathrm{H}_{3} \mathrm{IO}_{6}\right)\left(\mathrm{H}_{2} \mathrm{O}_{6}\right)\right]^{4-}\right.$ is considered as active species for the title reaction. It becomes apparent that in carrying out this reaction, the role of $\mathrm{pH}$ in the reaction medium is crucial. The overall mechanistic sequence described here is consistent with product studies, mechanistic studies and kinetic studies.

\section{Reference}

1 Chandra S and Yadav K L, Micrchem. J. 15(1), 1970, 15A, 78; Rozovoskii G I., Talaiene D, Jankauskas R and Z Anal. Khim. 1974, 29(11), 2243.

2 Rozovoskii G I, Misyavichyus A K A and Yu Prokopchik , Kinetikai kataliz., 1975 16(2), 402; Eng. Translation, Kinetics and Catalysis. 1975,16, 337.

3. Beck G, Mikrochem. 1952, 39, 313; Kovat, Z Acta Chim Hung 1959, 21, 247. ; Kovat, Z Acta. Chim. Hung 1960, 22, 313.

$4 \quad$ Movius W G, Inorg Chem. 1973, 12, 31.

5 Ram Reddy M G, Sethuram B and Navaneeth Rao T, Indian J Chem 1978, 16A, 31.

6 Bal Reddy K, Sethuram B and Navaneeth Rao T, Indian J.Chem 1981, 20A, 395; Padmavati J, and Yusiff K, Transition Met Chem. 2001, 6, 315; Reddy K, Sethuram. B and Navaneeth Rao T, Indian J. Chem. 1984, 23A, 593; Bal Reddy K, Sethuram B and Navaneeth Rao T, Z phys. Chemie. Leipzig. 1987, 268, 706.

7 Mahadevappa D S, Rangappa K S, Gow da N N M and Thimmegouda B, Int. J. Chem. Kinet 1986, 60, 589.

8 Mohanti M K and Laloo D, J. Chem. Soc. Dalton. Trans 1990, 311; Shanmugam R M and Subburamiyar TV, J. Chem. Soc. Perkin trans. 1988, II, 341.

9 Balreddy K, Sethuram B and Navaneeth Rao T, Indian J. Chem. 1981, 20A ,395.

10 list B, Lerner R A and Barbas C. F, J. Am. Chem. Soc. 2000, 122, 2395.

11 Jaiswal P K and Yadava K L, Indian J. Chem. 1973, 11, 837; Murthy C P, Sethuram B and Navaneeth Rao T, Z Phy. Chem. 1981, 262, 336. 
12 Jeffery G H, Bassett J, Mendham J and Denny R C, Vogel's Text book of Quantitative Chemical Analysis; 5th ed.; ELBS; Longman; Essex UK, 1996; 455.

Panigrahi G P and Misro P K, Indian J. Chem. 1978, 16A, 201.

Feigl F, Spot Tests in Organic Analysis; Elsevier: New York, 1975, 333.

Bellamy LJ, The Infrared Spectra of Complex Molecules; Methuen and Co.Ltd; London, 1958, 162. Svehla G , In Vogel's A I qualitative inorganic analysis; 7th ed.; Longman Ltd; London; 1998, 85.

Lide DR (Eds). CRC Hand Book of Chemistry and Physics; 73rd ed.; CRC press; London, 1992, 8-51. Kolthoff I .M , Meehan E J and Carr E M, J. Am. Chem. Soc. 1953, 75,1439; Bhattacharya S and Banerjee P, Bull. Chem. Soc. Japan 1996, 69, 3475.

19 Rozovoskii G I and Yankauskas R P, Tr. AN Lit SSR Ser; 967, B-41, 51, 73; Beck G, Mikrochem. Acta; 1956, 43, 977.

20 Bailar J C, Emeleus H J and Nyholm S R, Trotman-Dikenson, A.F. Comprehensive Inorganic Chemistry; Pergamon; Oxford, 1975; Vol. 2, 1456.

21 Chang $\mathrm{R}$, in Physical Chemistry with applications to Biological systems; McMillan; New York, 1981, 326.

22 Panari R G, Chougale R B and Nandibewoor S T, J. Phys. Org. Chem. 1998, 11,448.; Vivekanandan S, Venkatarao K, Sanatappa M and Shanmuganathan S P, Indian J. Chem. 1983, 22A , 244.; Baes C F and Jr. Mesmer R E., in the Hydrolysis of Cations; Wiley; New York, 1976, 224.

23 Mulla R M, Gurubasavaraj H M and Nandibewoor S T, Polish J. Chem. 2003, 77,1833.

24 Moore F M and Hicks K W, J. Inorg. Nucl. Chem. 1976, 38, 381; Farokhi S A, and Nandibew oor S T, Tetrahedron 2003, 59, 7595.

25 Lott K A K, Symons M C R, Discuss Faraday Soc. 1960, 29 105; Jaky M, Szevereneyi M and Simandi L I, Inorg. Chim. Acta 1991, 186, 33.

26 Rangappa K S, Raghavendra M P, Mahdevappa DS and Channagouda D J, J. Org. Chem. 1998, 63, 531.

27 Panari R G, Chougale R B and Nandibewoor ST, J. Phys. Org. Chem. 1998, 11, 448.

28 Leffler E, J. Org. Chem. 1955, 20, 1202.

29 Bal reddy K, Sethuram B and Navaneeth Rao T, Indian J. Chem., 1981, 20A, 397.

\section{APPENDIX}

According to Scheme 1 ,

Rate $=k[C]=k K_{5}[L-\text { proline }]_{\mathrm{f}}\left[\mathrm{Cu}^{4-}\right]_{\mathrm{f}}$

$=\mathrm{K} \mathrm{K}_{4} \mathrm{~K}_{5}\left[\mathrm{Cu}^{3}\right]\left[\mathrm{OH}^{-}\right][\mathrm{L}-$ proline $]$ Now,

$[\mathrm{DPC}]_{\mathrm{T}}=\left[\mathrm{Cu}(\mathrm{OH})_{2}\left(\mathrm{H}_{3} \mathrm{IO}\right)_{6}\right]^{3-}+\left[\mathrm{Cu}^{4-}\right]+\mathrm{C}$ $\left.=\left[\mathrm{Cu}^{3-}\right]_{\mathrm{f}}+\mathrm{K}_{4}\left[\mathrm{Cu}^{3-}\right]_{\mathrm{f}}\left[\mathrm{OH}^{-}\right]+\mathrm{K}_{5} \mathrm{Cu}^{4}\right][\mathrm{L}-$ proline $]$

$=\left[\mathrm{Cu}^{3-}\right]_{\mathrm{f}}+\mathrm{K}_{4}\left[\mathrm{Cu}^{3-}\right]\left[\mathrm{OH}_{\mathrm{f}}^{-}\right]+\mathrm{K}_{4} \mathrm{~K}_{5}\left[\mathrm{Cu}^{3-}\right][\mathrm{L}-$ proline $]\left[\mathrm{OH}^{-}\right]$

$=\left[\mathrm{Cu}^{3-}\right]_{\mathrm{f}}\left(1+\mathrm{K}_{4}\left[\mathrm{OH}^{-}\right]+\mathrm{K}_{4} \mathrm{~K}_{5}[\mathrm{~L}-\right.$ proline $\left.]\left[\mathrm{OH}^{-}\right]\right)$

Where $T$ and $f$ stand for total and free,

$$
\left[\mathrm{Cu}^{3-}\right]_{\mathrm{f}}=\frac{[\mathrm{DPC}]_{\mathrm{T}}}{1+\mathrm{K}_{4}\left[\mathrm{OH}^{-}\right]+\mathrm{K}_{4} \mathrm{~K}_{5}[\mathrm{~L} \text {-proline }]\left[\mathrm{OH}^{-}\right]}
$$

$$
\left[\mathrm{OH}^{-}\right]_{\mathrm{f}}=\frac{\left[\mathrm{OH}^{-}\right]_{\mathrm{T}}}{1+\mathrm{K}_{4}\left[\mathrm{Cu}^{3-}\right]+\mathrm{K}_{4} \mathrm{~K}_{5}[\text { L-proline }][\mathrm{DPC}]}
$$

$[\text { L-proline }]_{\mathrm{T}}$

$[\text { L-proline }]_{\mathrm{f}}=\overline{1+\mathrm{K}_{4} \mathrm{~K}_{5}\left[\mathrm{Cu}^{3-}\right]\left[\mathrm{OH}^{-}\right]}$

Substituting the values of equation (II), (III) and (IV) in equation (I) and omitting subscripts $\mathrm{T}$ and $\mathrm{f}$, we get

$$
\frac{\text { Rate }}{[\mathrm{DPC}]}=\frac{\mathrm{kK}_{4} \mathrm{~K}_{5}[\mathrm{~L}-\text { proline }]\left[\mathrm{OH}^{-}\right]}{1+\mathrm{K}_{4}\left[\mathrm{OH}^{-}\right]+\mathrm{K}_{4} \mathrm{~K}_{5}[\mathrm{~L}-\text { proline }]\left[\mathrm{OH}^{-}\right]}
$$




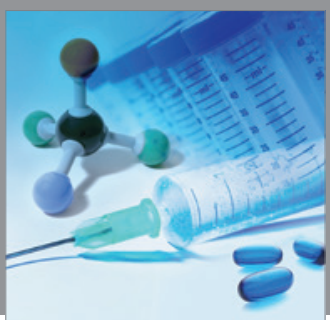

International Journal of

Medicinal Chemistry

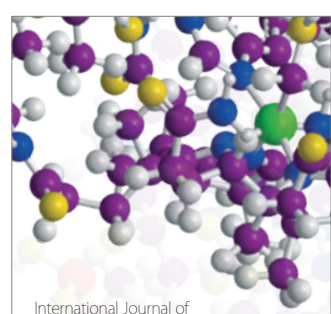

Carbohydrate Chemistry

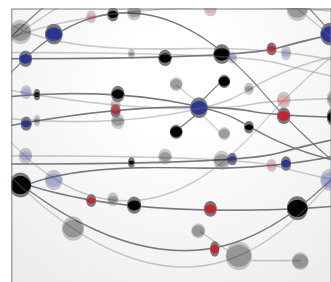

The Scientific World Journal
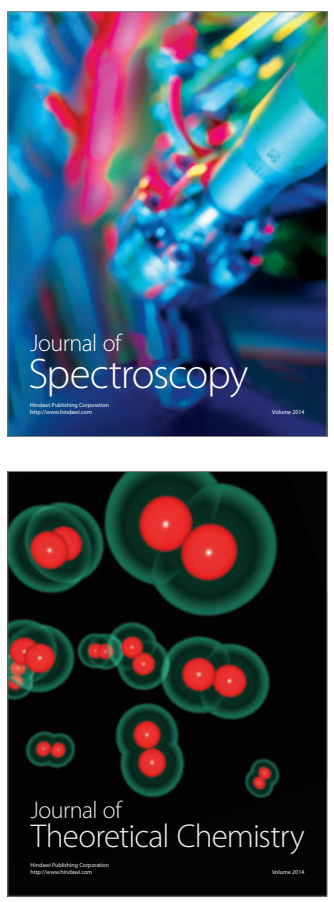
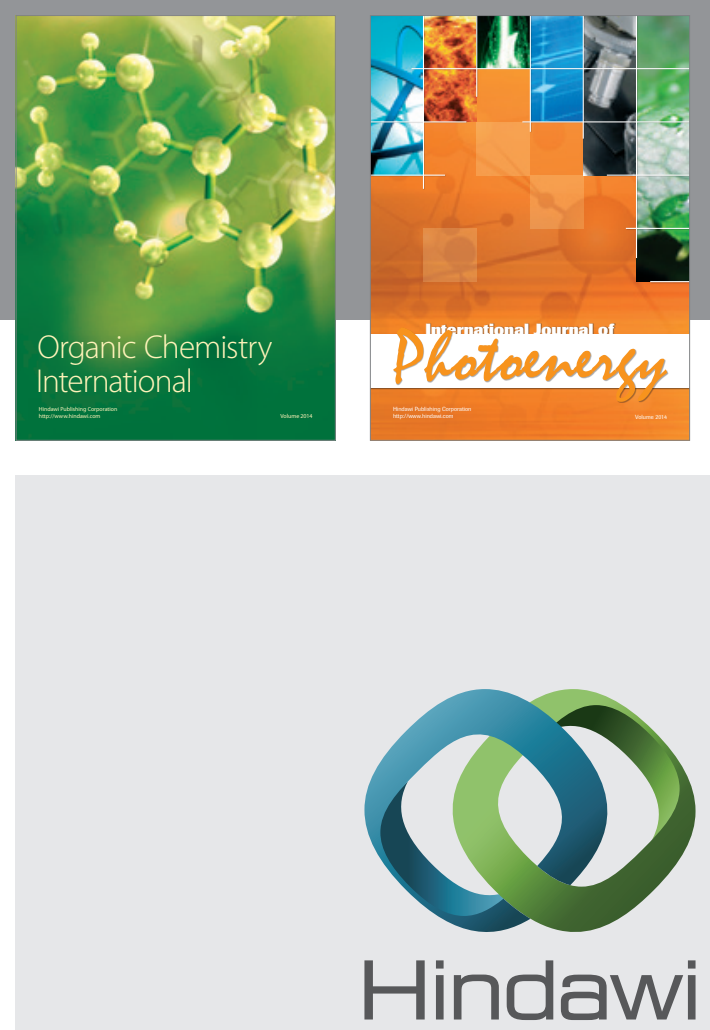

Submit your manuscripts at

http://www.hindawi.com
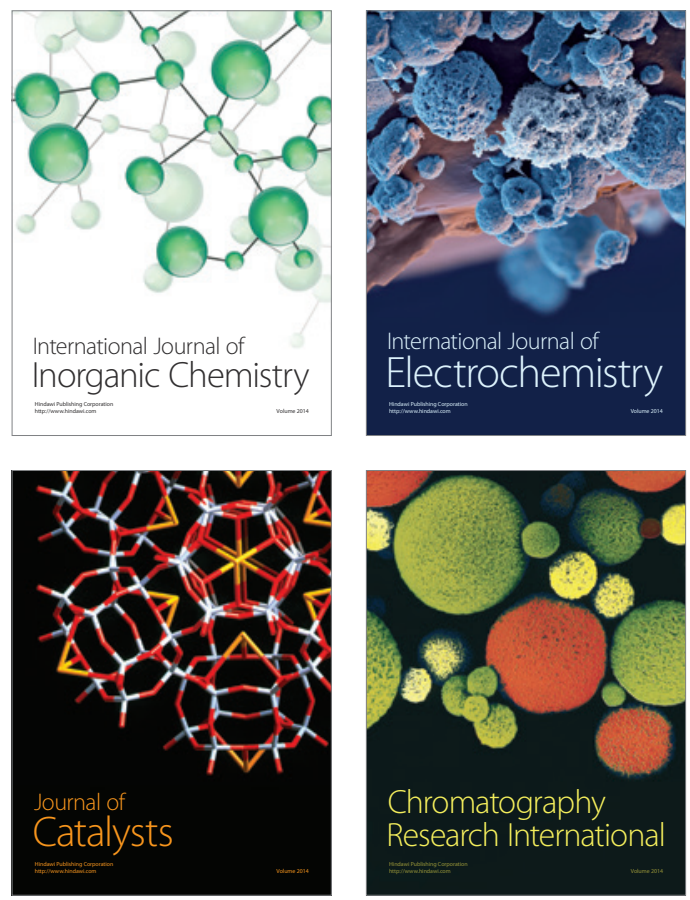
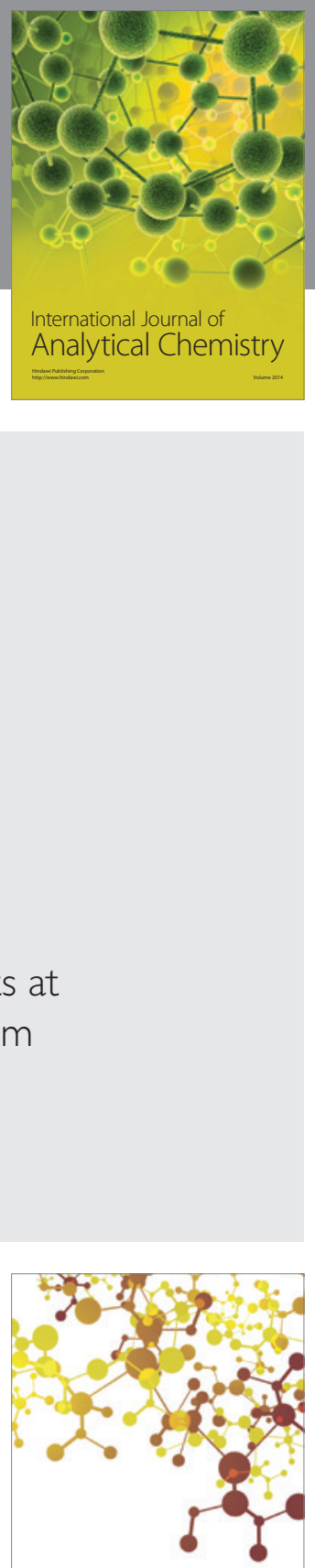

Journal of

Applied Chemistry
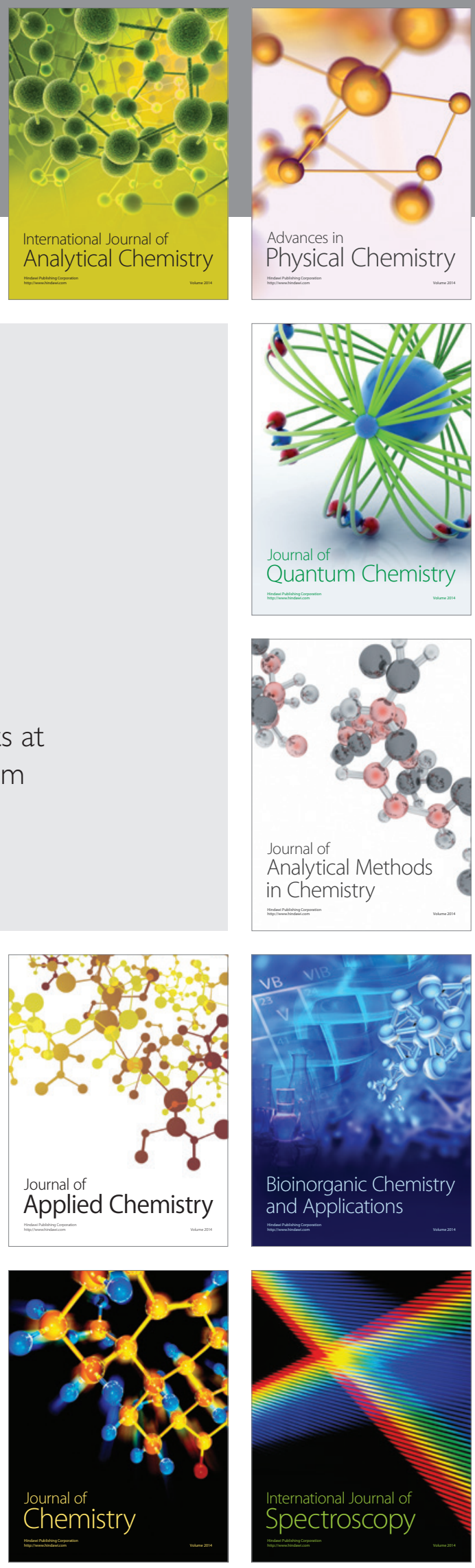